\title{
Effect of captivity on genetic variance for five traits in the large milkweed bug (Oncopeltus fasciatus)
}

\author{
KM Rodríguez-Clark ${ }^{1}$ \\ Department of Ecology and Evolutionary Biology, Princeton University, Princeton, NJ 08544, USA
}

\begin{abstract}
Understanding the changes in genetic variance which may occur as populations move from nature into captivity has been considered important when populations in captivity are used as models of wild ones. However, the inherent significance of these changes has not previously been appreciated in a conservation context: are the methods aimed at founding captive populations with gene diversity representative of natural populations likely also to capture representative quantitative genetic variation? Here, I investigate changes in heritability and a less traditional measure, evolvability, between nature and captivity for the large milkweed bug, Oncopeltus fasciatus, to address this question. Founders were collected from a $100-\mathrm{km}$ transect across the north-eastern US, and five traits (wing colour, pronotum colour, wing length, early fecundity and later fecundity) were recorded for founders and for their offspring during two
\end{abstract}

generations in captivity. Analyses reveal significant heritable variation for some life history and morphological traits in both environments, with comparable absolute levels of evolvability across all traits (0-30\%). Randomization tests show that while changes in heritability and total phenotypic variance were highly variable, additive genetic variance and evolvability remained stable across the environmental transition in the three morphological traits (changing 1-2\% or less), while they declined significantly in the two life-history traits $(5-8 \%)$. Although it is unclear whether the declines were due to selection or gene-by-environment interactions (or both), such declines do not appear inevitable: captive populations with small numbers of founders may contain substantial amounts of the evolvability found in nature, at least for some traits.

Heredity (2004) 93, 51-61. doi:10.1038/sj.hdy.6800479

Keywords: evolvability; heritability; morphological; life-history; captivity vs nature; captive breeding

\section{Introduction}

The presence of heritable variation is a basic prerequisite for evolutionary response to natural selection on a trait. Understanding how this variation changes when populations are brought from nature to captivity is important for two primary reasons. First, it is difficult, except in rare circumstances (eg, Milner et al, 2000), to obtain the information needed for quantitative genetic studies on free-living populations. Thus, studies are commonly made on populations in captivity and then extrapolated to make inferences about evolutionary forces in nature; the circumstances under which this extrapolation may be valid have been examined extensively (see Weigensberg and Roff, 1996 for review).

A second reason for examining changes across the nature-captivity transition, which has not been considered previously, is that threatened and endangered species are increasingly recommended for captive breeding (Balmford et al, 1996). Because such populations may remain in captivity for extended periods, and may become the only source for population recovery in the future, it is of inherent interest to understand how genetic variation might change upon captivity, since such variation, among

Correspondence: KM Rodríguez-Clark, Department of Ecology and Evolutionary Biology, Princeton University, Princeton, NJ 08544, USA. E-mail:kmrc@ivic.ve

${ }^{1}$ Current address: Centro de Ecología, Instituto Venezolano de Investigaciones Científicas (IVIC), Apartado 21827, Caracas 1020-A, Venezuela.

Received 21 March 2003; accepted 15 December 2003 other things, determines a population's ability to persist upon reintroduction (Bürger and Lynch, 1995).

Genetic variation available for response to selection has been measured traditionally as narrow-sense heritability, $h^{2}$, the ratio of additive genetic variance $\left(\sigma_{\mathrm{A}}^{2}\right)$ to total phenotypic variance $\left(\sigma_{\mathrm{P}}^{2}\right)$, itself composed of additive genetic, nonadditive genetic $\left(\sigma_{\mathrm{I}}^{2}\right)$, and environmental $\left(\sigma_{\mathrm{E}}^{2}\right)$ components: $\sigma_{\mathrm{A}}^{2} /\left[\sigma_{\mathrm{A}}^{2}+\sigma_{\mathrm{I}}^{2}+\sigma_{\mathrm{E}}^{2}\right]$ (Falconer and MacKay, 1996). Decomposed in this way, it is perhaps unsurprising that extensive study has failed to find consistent patterns of change from nature to captivity in this complex measure. Heritability may increase upon captivity simply because environmental components are reduced in more controlled conditions (eg, Simons and Roff, 1994) and may decrease in nature due to seasonal or annual environmental variation (eg, Sgró and Hoffmann, 1998). Similarly, it may remain stable if both environmental and genetic variance change proportionally (eg, Blanckenhorn, 2002).

A less traditional but perhaps better measure for assessing changing capacity to respond to selection across a variety of traits may instead be evolvability, the coefficient of additive genetic variation, $C V_{\mathrm{A}}=100 * \sqrt{\sigma_{\mathrm{A}}^{2}} / \bar{X}$, which depends only on additive genetic variance, standardized by the trait mean, $\bar{X}$ (Houle, 1992). At least three nonexclusive processes may influence changes in evolvability from nature to captivity: drift, selection and gene-by-environment interaction. Classic infinitesimal theory holds that $\sigma_{\mathrm{A}}^{2}$ should change in proportion to gene diversity, GD (equivalent to expected heterozygosity; Falconer and MacKay, 1996), 
such that no change in $\sigma_{\mathrm{A}}^{2}$ due to drift is expected unless the number of individuals used to found the captive population is very small, and/or the population remains small in subsequent generations. It is on the basis of this theory that it is often assumed that no more than 20 founders $(N)$ are needed for a captive-bred population, since they are expected to sample on average $1-1 /(2 N)$, or $97.5 \%$ of wild GD, and thus also nearly all wild additive genetic variance (Lacy, 1994). If additive assumptions do not hold, however, and $\sigma_{\mathrm{I}}^{2}$ is large, sampling-induced changes in allele frequencies may inflate $\sigma_{\mathrm{A}}^{2}$, causing increases in evolvability (Willis and Orr, 1993 and references therein).

A second process affecting changes in evolvability in nature vs captivity may be selection. Hedrick (1986) has argued that environmental heterogeneity is responsible for maintaining most polymorphic loci in natural populations, such that higher $\sigma_{\mathrm{A}}^{2}$ is expected in the wild, where it is maintained by heterogeneous selection. On the other hand, if populations are under mostly balancing selection in nature, $\sigma_{\mathrm{A}}^{2}$ may be expected to increase in the permissive conditions of captivity, as selection-induced linkage disequilibrium dissipates and/or mutations accumulate which would have otherwise been selectively removed (Prout and Barker, 1989). However, both balancing and directional selection in captivity ('domestication') may also cause rapid and large losses of $\sigma_{\mathrm{A}}^{2}$ (Rodríguez-Clark, 2002).

Finally, gene-by-environment interactions have been hypothesized to play an important role in determining immediate changes in $\sigma_{\mathrm{A}}^{2}$ from nature to captivity. Specifically, it has been suggested that greater $\sigma_{\mathrm{A}}^{2}$ may be expressed in more 'stressful' conditions, as would be characteristic of nature, allowing for rapid response to selection challenges there. Although the mechanisms underlying this stress-dependence hypothesis remain obscure, the findings of numerous studies appear consistent with this view. Nonadditive genetic variation has similarly been hypothesized to be at higher levels in the stressful conditions of nature (reviewed in Hoffmann and Parsons, 1991; Bijlsma and Loeschcke, 1997).

General conclusions about changes in evolvability from nature to captivity have been hampered in past studies by a focus on a few species, on only one trait in any given study, or on heritability exclusively as the parameter of interest. In the present paper, I address these issues by combining minimum estimates of heritability in nature and in captivity with estimates of phenotypic variability in both environments, to estimate changes in additive genetic variation and evolvability in five traits, in a well-characterized but underutilized experimental insect species.

\section{Methods}

\section{The study organism}

The basic data collected consist of three categories of observation - wing length, fecundity and colour - which are of particular interest in the context of the natural history of the large milkweed bug. Oncopeltus fasciatus experiences great environmental variation across its natural range, which covers much of North America and the Caribbean. A seed predator specializing on
Asclepias (milkweed) species, O. fasciatus is highly dependent on this patchy and ephemeral resource for reproduction. It is not thought to overwinter in the northern parts of its range, with these populations instead re-establishing every year with migrants from continuously reproducing southern ones, leading to likely panmixia within large geographic regions. This conclusion is supported by studies that have found quantitative and molecular genetic differentiation within the species only at the scale of thousands of kilometres (Leslie and Dingle, 1983; Leslie, 1990). Low temperatures, food limitation and short day lengths all induce flight restlessness and reproductive diapause in northern populations, suggesting that some late-autumn northern residents may escape frosts by flying south (RodríguezClark, 2002 and references therein). Wing length, the first trait examined in this study, appears to be an important character in this migratory syndrome, as it is genetically correlated with flight behaviour in northern populations (Dingle and Evans, 1987).

Another category of trait examined, fecundity, is also a part of this migratory syndrome. Unlike many insect species, female $O$. fasciatus will produce large numbers of (infertile) eggs even if virgin, which is thought to allow females to take advantage of patchily distributed mates and food as quickly as possible. Once females arrive at a suitable host, they deposit clutches of $\sim 30$ eggs per day (up to 2000 or more total) in protected crevices on the plant (Rodríguez-Clark, 2002 and references therein).

Colour comprises the final category of trait examined. As with many other milkweed specialists, O. fasciatus sequesters the plant's poisonous cardiac glycosides and has a contrasting black and coloured aposematic pattern effective against both vertebrate and invertebrate predators (Evans, 1988). The gregariousness of this species through the adult stage may be a further adaptation enhancing the aposematic effect. Colouring of hard body parts and the hemelytra (forewing) may vary considerably, from nearly white through yellow and orange to deep red. This study represents the first to explore the genetic basis of this variation.

\section{Field collections}

This experiment spanned three generations: Generation 0 (wild caught), 1 (lab-reared) and 2 (lab-reared), each of which contained 50 families. Individuals were collected between 18 and 27 September 1998, from 29 locations along a $350 \mathrm{~km}$ transect within the north-eastern United States (Figure 1).

The transect was constructed in order to sample within-subpopulation variation widely while ensuring unrelatedness among founders, as is recommended for captive populations of endangered species (Lacy, 1994), taking into account the species' long-distance dispersal and likely panmixia within broad geographic regions. Distance between sampling locations was $\sim 15 \mathrm{~km}$, as permitted by the patchy population distribution. Within each location, individuals or clusters of bugs were collected from 2 to 10 common milkweed plants (Asclepias syriaca), between $100 \mathrm{~m}-1 \mathrm{~km}$ apart. Migrating adults tend to stay in a suitable patch once they find one, and hatched broods usually stay together on a single plant at least until the third instar, with subsequent moves of usually less than a meter (Dingle, 1981). Thus, 


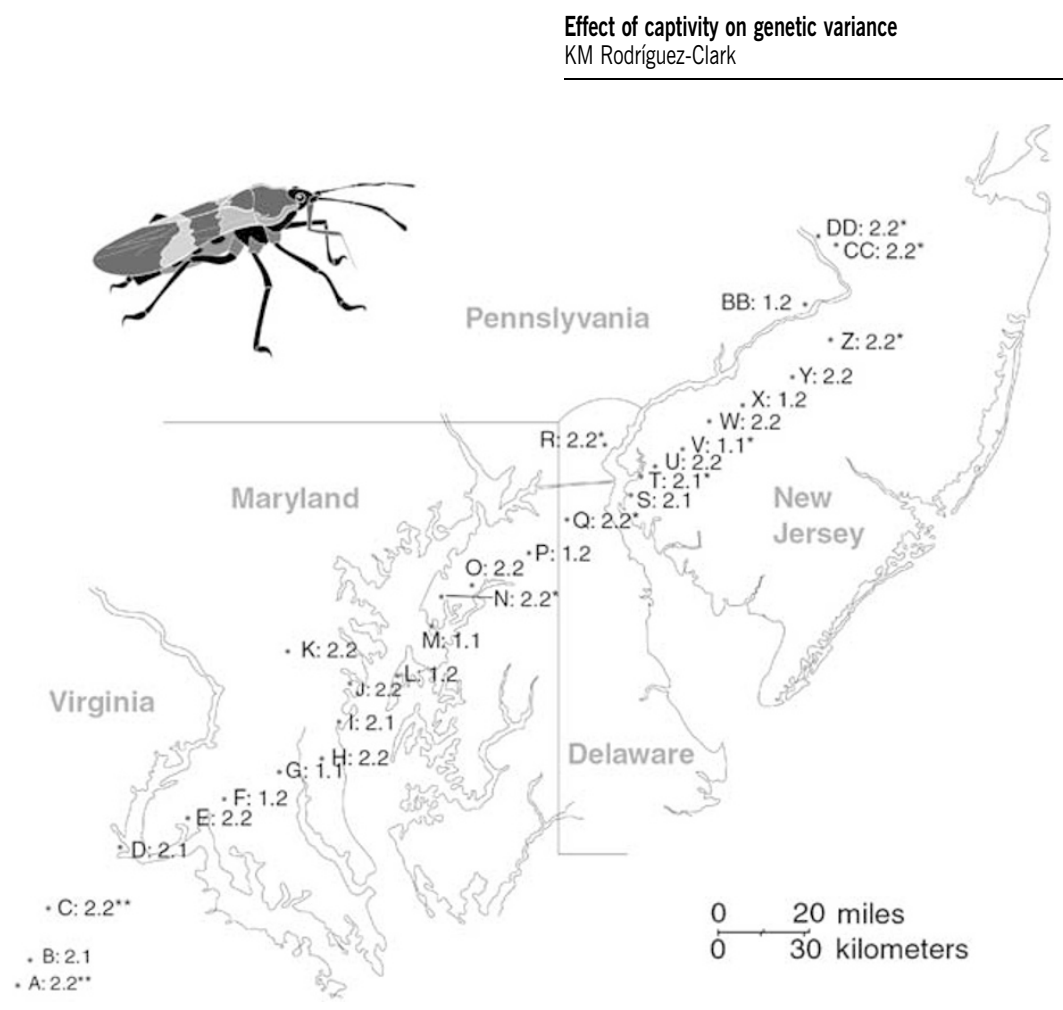

Figure 1 Locations across the north-eastern USA from which 50 founding individuals were collected. Points indicate sampling locations with sex ratio of founders used from that location (males.females). Asterisks indicate number of possible sibling pairs captured.

bugs found together on a plant or in a patch of plants were conservatively considered to be a 'sibship'.

Very recently eclosed adults or 5 th instars (just prior to sexual maturity) were preferentially collected, so that most development occurred under natural conditions, but females were still virgin. Of the hundred wild individuals used to form Generation 0 , at collection, 25 were recently eclosed adults, 60 were 5th instar, 11 were 4 th instar, three were 3 rd instar and two were 2 nd instar.

Presumed sibships were maintained as groups upon capture, with males and females separate. Individuals are easily sexed at both the 5 th instar (when females have two dark spots on their posterior segments, while males have one) and as adults, when females have a caudal median point on the posterior margin of the 4 th abdominal sternite, as well as a triangular cleft pygidium, unlike the more rounded male structure (Rodríguez-Clark, 2002).

\section{Culture techniques}

In general, bugs were maintained in captive conditions as close as possible to those typical in the wild during the season of maximal reproduction: northern latitude midsummer. Groups were maintained in $9.5 \times 9.5 \times 9.5 \mathrm{~cm}$ re-usable polystyrene boxes (Pioneer Packaging, model 29-C), each with a sheer fabric aeration window in the removable lid, which was secured with a rubber band. In Generation 0, groups larger than 10 were split so that density was never higher than 10 individuals/box, giving each bug at least $82 \mathrm{~cm}^{3}$, well in excess of the $35 \mathrm{~cm}^{3}$ minimum necessary to avoid densitydependent growth effects (Koerper and Jorgensen, 1984).

In Generations 1 and 2, once eggs were laid and weighed (see below), sibships were divided among four boxes, with 10 eggs placed in each box using a sable paintbrush, to provide an excess of individuals for the next generation. Labelled boxes were assigned random locations within the rearing chamber. Upon reaching the 5th instar, males and females in each family were sorted and redistributed among their four boxes, maintaining sexes separate and densities at no more than 10 bugs/ box. A band of liquid Teflon (Northern Products Inc., Woonsocket, RI, USA) was painted on the inside rim of each box as an additional safeguard against escapes by smaller instars. Each box was provided with ad libitum deionized water in a disposable $37 \mathrm{ml}$ vial with a cotton wick, secured to the base of the box with nontoxic poster gum.

Individuals were reared on ripe milkweed seeds from a variety of wild sources. Ripened pods were collected from the vicinity of Princeton, New Jersey, in the autumns of 1997 and 1998, and seeds were removed either by hand or according to methods described by Feir et al (1982). To randomize effects of seed age on nutrition, these fresh seeds were mixed periodically with $>1$-yearold seed purchased commercially (Valley Seed Service, Fresno, CA, USA), and older seeds obtained from Missouri and Minnesota. Seeds were stored in airtight containers with indicating silica gel to prevent mould growth.

O. fasciatus from north-eastern populations fed ad libitum are indistinguishable in size and survivorship from those given 12 seeds per bug from egg to eclosion (Dingle, 1992), equivalent to $0.7 \mathrm{~g}$ for $10 \mathrm{bugs}$. To provide well in excess of this amount, $\sim 1.5 \mathrm{~g}$ seed was scattered on the bottom of each box. Rearing boxes were kept at $28 \pm 1{ }^{\circ} \mathrm{C}$ with humidity maintained at $50-70 \%$, on a schedule of $16 \mathrm{~h}$ light $8 \mathrm{~h}$ dark. These conditions maintain optimal egg production and minimal probability of diapause, with $\sim 27$ days between hatch and adult metamorphosis, and 10 additional days to first 
reproduction (Groeters and Dingle, 1988). Boxes were kept on clear Plexiglas trays on wire shelving, to maximize light penetration to all groups.

\section{Husbandry}

The 50 mating pairs in Generation 0 were created by selecting one or two each of mature males and females captured at each sampling location, all from different presumed sibships where possible (never using individuals of the same sex from the same sibship). These 100 individuals were then paired randomly, avoiding possible sib matings. Two adult offspring (one of each sex) from each pair were again chosen arbitrarily to form Generation 1, and were paired randomly, avoiding sib matings, to give rise to Generation 2. If offspring reached maturity prior to separation, females found in a box with males were discarded. All pairs were made at least in quadruplicate to guard against family loss, with one replicate selected randomly to contribute to the next generation.

Pairs were placed in plastic Petri dishes, $9 \mathrm{~cm}$ diameter $\times 2.5 \mathrm{~cm}$ height, with a $14.8 \mathrm{ml}$ disposable water vial with a cotton wick and $\sim 20$ fresh seeds $(0.12 \mathrm{~g})$. The mouth of each dish was covered with 40x32-denier wrinkled cotton gauze secured with a rubber band and the dish lid. Dishes were kept entirely dark, inside cardboard trays with cardboard coverings. Under these circumstances, $O$. fasciatus from northern populations deposit eggs almost exclusively through wrinkled areas in the gauze onto the dish lid, allowing eggs to be easily removed (H Dingle, D Feir, personal communication). This set-up provided a total laying area of $\sim 64 \mathrm{~cm}^{2}$ per female (more than the $40 \mathrm{~cm}^{2}$ minimum required for optimal egg production; Koerper and Jorgensen, 1984).

\section{Measurement of traits}

Just prior to creating mating pairs, wing length and colour traits were assessed on the right-hand side of all individuals, at the same age (30-35 days posthatch) and at least 2 days posteclosion, when the cuticle hardens and final adult colour and dimensions have stabilized. Individuals were anaesthetized with carbon dioxide on a fritted glass microscope stage, and placed on a customdesigned brass cradle, using dental wax to hold wings flat (Figure 2a). Bugs were photographed using a Polaroid Digital Microscope Camera with a glass-etched $2 \mathrm{~mm}$ scale bar adjusted to be exactly at the focal plane. For each picture, $X-Y$ coordinates were recorded for both ends of the scale bar as well as for the wing tip and the proximal posterior wing process, using Scion Image software (2000) on a PC (Figure 2b). Wing length (WL) was taken as the distance between these two points in $\mathrm{mm}$. Repeatability for this trait was 99\% (40 individuals measured 10 times each; $\mathrm{F}=638, P<0.0001)$.

Colours on parts of the pronotum (PC) and forewing (WC) (Figure 2b) were assessed by comparing individuals to a colour bar created freshly from standard colour chips each generation. Although colour in this species varies nearly continuously, the range was divided into a 5-unit scale in order to have enough classes to treat the data as continuous, but few enough to minimize classification error ( $1=$ light yellow \#1215; $2=$ yellow-orange $\# 1225 ; 3=$ orange \#116, 2X; $4=$ redorange \#130, 2X; $5=$ red \# 165, 2X; Letraset Ltd., 1998).
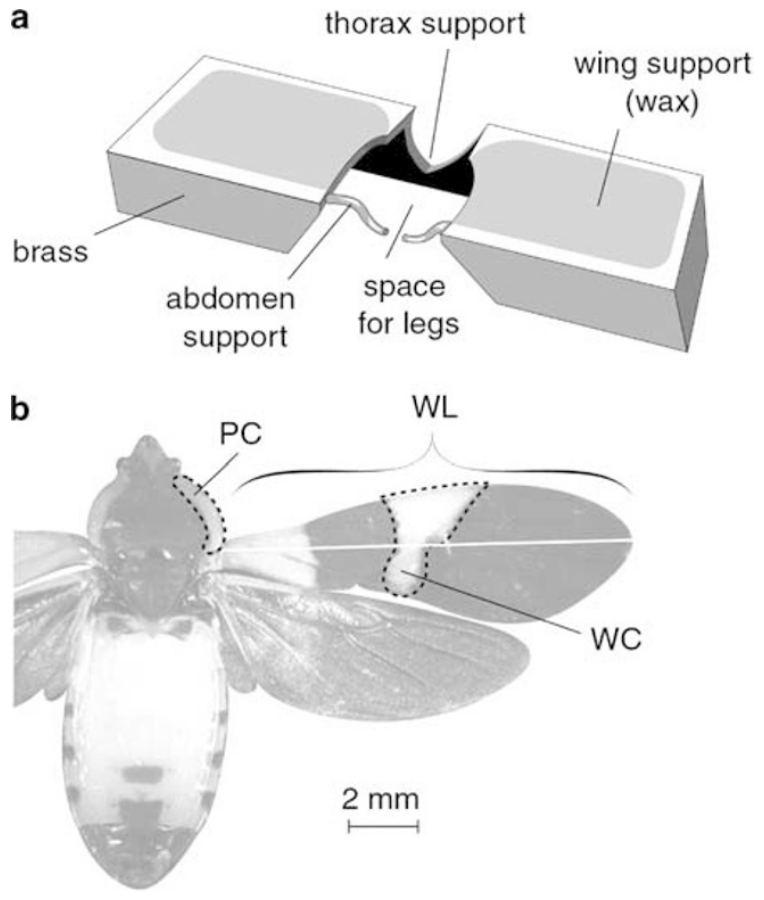

Figure 2 (a) Cradle used to immobilize live bugs for microscope photography. (b) Morphological traits measured (WL=wing length; $\mathrm{PC}=$ pronotum colour; $\mathrm{WC}=$ wing colour)

Repeatability was $94 \%$ for wing colour (50 individuals measured 10 times each, $\mathrm{F}=142, P<0.0001$ ), and $66 \%$ for pronotum colour $(\mathrm{F}=20, P<0.0001)$. A Meiji TechnoRZ zoom stereo microscope $(10 \times$ magnification) and V-Lux 1000 light source set to maximum were used throughout. Values for colours and wing length were recorded for both parents and eight randomly selected offspring per family (four each males and females).

For individual females, the rate of egg production following mating has been found to be highly correlated with the lifetime quantity of eggs produced, as well as average clutch size and total fecundity by weight (Leslie, 1990). Total mass of eggs laid during two time spans was thus recorded for each wild female, using a modification of Palmer and Dingle (1986) and Groeters and Dingle (1996): (1) from pair creation to 5-6 days afterward, and (2) from that point to 9-12 days afterward. All eggs were weighed on glassine paper using a Sartorious R200D electronic semi-microbalance. Masses were converted into $\mathrm{mg}$ /day production rates ('early fecundity', EF and 'later fecundity', LF) by dividing by the number of full days elapsed between mating and first weighing or between the first and second weighing dates, respectively.

Egg mass was considered to be a function of the maternal generation, following Palmer and Dingle (1986), in recognition of the overwhelming likelihood of maternal effects in this and other egg characters (Lynch and Walsh, 1998). Sperm storage in females prevents the use of more than one male per female, so male influence on the trait could not be separately assessed. Egg mass was recorded for each dam and for four (Generation 1) or eight (Generation 2) of her female offspring at the same age. 
Statistical analyses

Heritability in captivity, $h_{\mathrm{C}}^{2}=\sigma_{\mathrm{AC}}^{2} / \sigma_{\mathrm{PC}}^{2}$, is estimated by $b_{\left(M O_{\mathrm{c}} \cdot M P_{\mathrm{c}}\right)}$, the regression of mid-offspring on mid-parent values, or $2 * b_{\left(M D_{\mathrm{c}} \cdot D_{\mathrm{c}}\right)}$, twice the regression of middaughter on dam values, with both generations reared in captivity (Generations 1 and 2) (Falconer and MacKay, 1996). $V_{\mathrm{PC}}$ an estimate of the total phenotypic variance $\left(\sigma_{\mathrm{PC}}^{2}\right)$, was obtained from the total variance within dams or sires for single-sex estimates, or pooled across sexes for two-sex estimates. Additive genetic variance in captivity $\left(\sigma_{\mathrm{AC}}^{2}\right)$ was estimated by $V_{\mathrm{AC}}=h_{\mathrm{C}}^{2} * V_{\mathrm{PC}}$. Residual variation in captivity $\left(\sigma_{\mathrm{RC}}^{2}\right.$, nonadditive genetic and environmental variance combined) was estimated as $V_{\mathrm{RC}}=V_{\mathrm{PC}}-V_{\mathrm{AC}}$, and the coefficient of additive genetic variation $\left(C V_{\mathrm{A}}\right)$ was estimated as defined in the Introduction.

Two consecutive generations were not available in nature, so estimation in this environment is less straightforward. Coyne and Beecham (1987), Prout and Barker (1989), and Riska et al (1989) together develop the relationships among three different estimates of heritability in nature, $h_{\mathrm{N}}^{2}$. The first of these, $h_{\mathrm{NV}}^{2}$, assumes constancy of $\sigma_{\mathrm{A}}^{2}$ across environments, and is given by $h_{\mathrm{NV}}^{2}=V_{\mathrm{AC}} / V_{\mathrm{PN}}$, in which $V_{\mathrm{PN}}$ estimates $\sigma_{\mathrm{PN}}^{2}$, the total phenotypic variance in parents from nature (Generation $0)$. When $\sigma_{\mathrm{A}}^{2}$ is lower in captivity than in nature, $h_{\mathrm{NV}}^{2}$ will be an underestimate of the true heritability in nature.

Using the fact that the regression of captive offspring on parents from nature $\beta_{\left(M O_{C} \cdot M P_{\mathrm{N}}\right)}$ is defined as $\gamma \sigma_{\mathrm{AC}} \sigma_{\mathrm{AN}} / \sigma_{\mathrm{PN}}^{2}$ (Lande in Coyne and Beecham, 1987), with some rearrangement, the second estimate of heritability in nature, $\gamma^{2} h_{\mathrm{N}}^{2}$, is given by

$$
\gamma^{2} h_{\mathrm{N}}^{2}=b_{\left(M O_{\mathrm{c}} \cdot M P_{\mathrm{N}}\right)}^{2}\left(\frac{V_{\mathrm{PN}}}{V_{\mathrm{AC}}}\right)
$$

in which $b_{\left(M O_{c} \cdot M P_{\mathrm{N}}\right)}^{2}$ is the squared estimate of $\beta_{\left(M O_{c} \cdot M P_{\mathrm{N}}\right)}$, and $\gamma$ is the additive genetic correlation between the trait in nature and in captivity. $\gamma$ is high when the rank ordering of genotype performances in both environments is the same, and low when it is not, when norms of reaction cross (Coyne and Beecham, 1987), so that this estimate is biased when $|\gamma|<1$.

The final estimate of heritability in nature, $h_{\mathrm{N} \beta}^{2}$ is defined as $\beta_{\left(M O_{\mathrm{c}} \cdot M P_{\mathrm{N}}\right)}$ and is estimated by $b_{\left(M \mathrm{O}_{\mathrm{c}} \cdot M P_{\mathrm{N}}\right)}$. It contains both sources of bias: it assumes both that $|\gamma|=1$ and that $\sigma_{\mathrm{A}}^{2}$ is constant across environments.

Based on the relationships among these three estimates of heritability in nature, Riska et al (1989) develop a parameter $\kappa$, which is defined as

$$
\kappa=\frac{h_{\mathrm{NV}}^{2}}{\beta_{\left(M O_{\mathrm{c}} \cdot M P_{\mathrm{N}}\right)}}=\frac{\beta_{\left(M O_{\mathrm{c}} \cdot M P_{\mathrm{N}}\right)}}{\gamma^{2} h_{\mathrm{N}}^{2}}=\frac{\sigma_{\mathrm{AC}}}{\gamma \sigma_{\mathrm{AN}}}
$$

and is estimated in this study by $k=h_{\mathrm{NV}}^{2} / h_{\mathrm{N} \beta}^{2}$. Because of the conditions in which these estimates are biased, when $k<1$, it follows that $h_{\mathrm{NV}}^{2}<h_{\mathrm{N} \beta}^{2}<\gamma^{2} h_{\mathrm{N}}^{2}$ and that additive genetic variance is greater in nature than in captivity and furthermore, that $\gamma^{2} h_{\mathrm{N}}^{2}$ is the best approximation of the lower bound of heritability in nature. Conversely, when $k>1, h_{\mathrm{NV}}^{2}>h_{\mathrm{N} \beta}^{2}>\gamma^{2} h_{\mathrm{N}}^{2}$, and $k$ provides no information about the relationship between additive variance in the two environments, nor which of the estimates of heritability in nature is the best (though $\gamma^{2} h_{\mathrm{N}}^{2}$, as the smallest, is most conservative).
Quantitative genetic parameters based on family relationships may be unreliable if there are significant gender differences in the means or variances of traits under consideration, or if data do not fit the assumptions of tests performed (Falconer and MacKay, 1996). Thus, prior to conducting the above analyses, all traits were examined for normality of residuals, with sexes both apart and combined, as well as for nonrandom associations between means and variances, and were transformed as needed (see Results). Differences in mean across sexes and generations in colours and length were examined using a 2-way ANOVA, while differences across generations in egg mass were examined with a Kruskal-Wallis test. Differences in variance were tested using Levene's test (SAS Institute Inc., 2001). Where the sexes differed systematically in mean, this was corrected by adding to each member of the smaller sex the average difference between female and male means (Norry et al, 1997). Following transformation, all analyses were conducted on both sexes separately to look for sexspecific effects, before combining sexes for final analyses if no differences were found.

Because of the complex, composite, nature of many of the statistics estimated in this study, parametric standard errors may be either unreliable, cumbersome to calculate, and/or simply unavailable (Lynch and Walsh, 1998, p. 560). The distributions of all statistics were thus estimated empirically using the bootstrap, following Riska et al (1989) and Manly (1997). In all, 50 family units (keeping parents with their associated offspring) were sampled independently with replacement from Generations $0-1$ and 1-2 for 2000 replicates. All statistics were calculated for each replicate; bias-corrected parameter estimates were produced for the original data set following Efron and Tibshirani (1986), while the standard deviations of the empirical distributions were used to estimate standard errors of all statistics (Manly, 1997).

Hypothesis testing is similarly complicated when composite statistics are the subject of comparison. Although individual regression coefficients could be tested for difference from 0 and from each other using standard F and homogeneity-of-slopes methods, direct comparison of estimates from nature and captivity (when the two are estimated using different methods or are themselves combinations of other estimates) is cumbersome or not possible with traditional largesample approximations (Lynch and Walsh, 1998, pp. 561, 807). Hence, cross-environment differences were tested using randomization, using the ratio of the larger to smaller estimate as the test statistic for both variance components and the additive coefficient of variation (Manly, 1997). For each comparison, the test statistic was calculated for the original data, then parents were randomized with respect to offspring, leaving each in their respective generations, and the test statistic was recalculated for each of 5000 replicates. This 'restricted randomization' tests for changes in variance across environments while holding mean effects constant (that is, correcting for any overall mean difference in offspring across generations; Petraitis et al, 2001). The probability of the observed test statistic was then taken as its location to the nearest percentile in the empirical distribution of 5000 test statistics. All analyses were conducted on a PC using Statistical Analysis System procedures (SAS Institute Inc., 2001). 


\section{Results}

\section{Trait distributions}

The distributions of wing colour (WC) and pronotum colour (PC) were remarkably constant across different rearing environments, although the pronotum was on average $\sim 1$ unit darker than the wing, and less variable (Table 1). There was a slight and significant trend toward females being darker than males in pronotum colour $(\mathrm{F}=10.8, P<0.001)$, and a similar nonsignificant trend in wing colour, so values for males were corrected by adding the average difference between males and females to each male value. The phenotypic correlation between WC and PC was moderate (Spearman's rank coefficient $=0.56, P<0.0001$ ), such that individuals with darker wings tended to have darker pronota; however, neither was correlated with other traits considered.

Average wing lengths (WL) in both environments (Table 1) were comparable to those recorded in previous studies (Groeters and Dingle, 1996). As with colour traits, WL differed consistently between sexes, with females larger $(\mathrm{F}=1326, P<0.0001)$ and more variable $(\mathrm{F}=8.5$, $P=0.004)$. This correlation of mean and variance held across generations as well, so wing lengths were $\mathrm{ln}$ transformed, and the mean difference between female and male lengths was then added to each male length. WL was not phenotypically correlated with any other trait in the study.

In contrast to morphological traits, distributions of egg production rates (early fecundity, EF and later fecundity, LF) changed greatly across rearing environments (Table 1). Mean production rates increased significantly each generation $(H=203, P<0.0001$ for $E F, 362.5$ $P<0.0001$ for $L F)$, and variability increased with mean production $(\mathrm{F}=35.2$ for $\mathrm{EF}, 59.8$ for $\mathrm{LF}, P<0.0001)$. Simple ln-transformation did not remove the dependence of variance on mean in these traits, so EF and LF were both transformed using Kleczkowski's method (Lynch and Walsh, 1998, p. 300). The phenotypic correlation between the two measures was moderate (Spearman's rank coefficient $=0.54, P<0.0001$ ), and neither was phenotypically correlated with any other trait.
Heritabilities, variance components and errors

Heritabilities were significantly different from zero in captivity for all three morphological traits, and in nature for the two colour traits and for early fecundity (Table 2). Although differences in single-sex estimates indicate the possibility of slight maternal effects for wing colour in captivity, differences were not significant, so midparentmidoffspring estimates were used in all subsequent analyses. Similarly, in estimates from nature, there was a trend toward a paternal effect on pronotum colour (PC) and a maternal effect on wing length (WL), but, in the absence of significant differences, sexes were combined in further analyses.

Analysis of changes in heritability in wing colour (WC) across environments is the most straightforward of all traits; all three estimates of $h_{\mathrm{N}}^{2}$ were high $(0.90-0.92)$ and virtually identical to each other, as well as to the estimate of $h_{\mathrm{C}}^{2}(0.92)$ (Table 2). $\mathrm{k}_{\mathrm{WC}}$ thus was $\sim 1$, indicating that $\gamma$ $\approx 1$, and that $V_{\mathrm{A}}$ for WC remained constant between nature and captivity. Pronotum colour (PC), despite its phenotypic correlation with WC, displayed a slightly different pattern. All three estimates of $h_{\mathrm{N}}^{2}(0.76-1.00)$ exceeded $h_{\mathrm{C}}^{2}(0.59)$, indicating a decline in heritability upon captivity. $k$ was just slightly larger than 1, indicating that despite the decline in heritability, additive variance remained essentially unchanged. Although in these circumstances, the data do not indicate which of the three estimates in nature is most accurate, the estimate of $\gamma^{2} h_{\mathrm{N}}^{2}$ was used in later analyses, as it is the most conservative.

In the case of wing length (WL), the three estimates for heritability in nature range from considerably more to considerably less $(0.55-0.02)$ than that in captivity $(0.34)$, and $k$ is 6.05 (much larger than 1), indicating that no information is available from this level of analysis regarding changes in heritability or additive genetic variance from nature to captivity in this trait.

However, both fecundity traits (EF and LF) were associated with a $k$ below 1 ( 0.29 and 0.21 , respectively), indicating a decline in additive genetic variance in captivity in both cases (Table 2). Although Riska et al (1989) assert that in cases where $k<1, \gamma^{2} h_{\mathrm{N}}^{2}$ is the best estimator of $h_{\mathrm{N}}^{2}$, the low estimate of $V_{\mathrm{A}}$ in captivity for both of these traits in this case makes the estimator

Table 1 Summary statistics for five traits in wild-caught and laboratory reared O. fasciatus (original measurement scales)

\begin{tabular}{|c|c|c|c|c|}
\hline \multirow[t]{2}{*}{ Trait } & \multirow[t]{2}{*}{$\operatorname{Sex}$} & \multicolumn{3}{|c|}{ Generation } \\
\hline & & 0 (nature) & 1 (captivity) & 2 (captivity) \\
\hline $\begin{array}{l}\text { Wing colour } \\
\text { (units) }\end{array}$ & $\begin{array}{l}\mathrm{f} \\
\mathrm{m}\end{array}$ & $\begin{array}{l}3.02 \pm 1.06(n=50) \\
3.06 \pm 1.08(n=50)\end{array}$ & $\begin{array}{l}3.24 \pm 0.99(n=192) \\
3.14 \pm 1.09(n=201)\end{array}$ & $\begin{array}{l}3.31 \pm 0.93(n=200) \\
3.19 \pm 0.95(n=200)\end{array}$ \\
\hline $\begin{array}{l}\text { Pronotum colour } \\
\text { (units) }\end{array}$ & $\begin{array}{c}\mathrm{f} \\
\mathrm{m}\end{array}$ & $\begin{array}{l}4.08 \pm 0.40(n=50) \\
3.96 \pm 0.45(n=50)\end{array}$ & $\begin{array}{l}4.02 \pm 0.52(n=192) \\
3.90 \pm 0.54(n=201)\end{array}$ & $\begin{array}{l}4.05 \pm 0.48(n=200) \\
3.96 \pm 0.53(n=200)\end{array}$ \\
\hline $\begin{array}{l}\text { Wing length } \\
(\mathrm{mm})\end{array}$ & $\begin{array}{c}\mathrm{f} \\
\mathrm{m}\end{array}$ & $\begin{array}{l}13.13 \pm 0.54(n=50) \\
11.74 \pm 0.48(n=50)\end{array}$ & $\begin{array}{l}12.77 \pm 0.66(n=198) \\
11.51 \pm 0.55(n=206)\end{array}$ & $\begin{array}{l}12.97 \pm 0.50(n=200) \\
11.61 \pm 0.45(n=200)\end{array}$ \\
\hline Early fecundity (mg/day) & $\mathrm{f}$ & $0.68 \pm 1.84(n=183)$ & $3.68 \pm 4.07(n=208)$ & $5.35 \pm 3.77(n=399)$ \\
\hline Later fecundity (mg/day) & $\mathrm{f}$ & $1.19 \pm 2.58(n=183)$ & $1.01 \pm 1.71(n=208)$ & $7.65 \pm 4.28(n=399)$ \\
\hline
\end{tabular}

Results presented as mean \pm SD (sample size). 
Table 2 Heritability analysis for five traits in O. fasciatus in nature and captivity

\begin{tabular}{|c|c|c|c|c|c|c|c|c|c|}
\hline \multirow[t]{2}{*}{ Trait } & & \multicolumn{5}{|c|}{ Estimates of $\mathrm{h}_{N}^{2}$} & \multirow[t]{2}{*}{$k$} & \multirow[t]{2}{*}{$\mathrm{h}_{C}^{2}(S E)$} & \multirow[t]{2}{*}{$\Delta N$ to $C$} \\
\hline & & $\mathrm{h}_{V N}^{2}$ & & $\mathrm{~h}_{N \beta}^{2}$ & & $\gamma^{2} \mathrm{~h}_{N}^{2}$ & & & \\
\hline Wing colour & $\begin{array}{l}\mathrm{MO} \\
\text { SS } \\
\text { DD }\end{array}$ & $\begin{array}{l}0.90 \\
0.93 \\
0.80\end{array}$ & $=$ & $\begin{array}{l}0.91^{* * *} \\
1.12^{* * *} \\
0.99^{* * *}\end{array}$ & $=$ & $\begin{array}{l}0.92 \\
1.34 \\
1.22\end{array}$ & 0.98 & $\begin{array}{l}0.92(0.06)^{* * *} \\
0.77(0.13)^{* * *} \\
1.07(0.19)^{* * *}\end{array}$ & $\begin{array}{l}\text { No change } V_{\mathrm{A}} \\
\text { No change } h^{2}\end{array}$ \\
\hline Pronotum colour & $\begin{array}{l}\text { MO } \\
\text { SS } \\
\text { DD }\end{array}$ & $\begin{array}{l}1.00 \\
1.13 \\
0.82\end{array}$ & $>$ & $\begin{array}{l}0.87^{* * *} \\
0.87^{* * *} \\
0.56^{*}\end{array}$ & $>$ & $\begin{array}{l}0.76 \\
0.68 \\
0.39\end{array}$ & 1.15 & $\begin{array}{l}0.59(0.10)^{* * *} \\
0.58(0.19)^{* * *} \\
0.58(0.20)^{* * *}\end{array}$ & $\begin{array}{l}\text { No change } V_{\mathrm{A}} \text { ? } \\
\text { Decrease } h^{2} ?\end{array}$ \\
\hline Wing length & $\begin{array}{l}\text { MO } \\
\text { SS } \\
\text { DD }\end{array}$ & $\begin{array}{l}0.55 \\
0.48 \\
0.62\end{array}$ & $>$ & $\begin{array}{l}0.09 \\
0.04 \\
0.20\end{array}$ & $>$ & $\begin{array}{l}0.02 \\
0.002 \\
0.06\end{array}$ & 6.05 & $\begin{array}{l}0.34(0.07)^{* * *} \\
0.34(0.15)^{*} \\
0.35(0.12)^{* *}\end{array}$ & $\begin{array}{l}\text { No info } V_{\mathrm{A}} \\
\text { No info } h^{2}\end{array}$ \\
\hline Fecundity (E) & DD & 0.13 & $<$ & $0.44^{*}$ & $<$ & 1.50 & 0.29 & $0.20(0.18)$ & $\begin{array}{l}\text { Decrease } V_{\mathrm{A}} \\
\text { Decrease } h^{2} \text { ? }\end{array}$ \\
\hline Fecundity (L) & DD & 0.018 & $<$ & 0.08 & $<$ & 0.40 & 0.21 & $0.07(0.22)$ & $\begin{array}{l}\text { Decrease } V_{\mathrm{A}} \\
\text { No info } h^{2}\end{array}$ \\
\hline
\end{tabular}

$\mathrm{MO}=$ mid-parent/offspring; $\mathrm{SS}=$ sons on sires; $\mathrm{DD}=$ daughters on dams. See text for detailed definitions of heritability estimates. Asterisks indicate that $h_{\mathrm{N} \beta}^{2}$ differs significantly from 0 at $P<0.05,0.01$ and 0.001 , respectively ( $h_{\mathrm{VN}}^{2}$ and $\gamma^{2} h_{\mathrm{N}}^{2}$ not tested). Changes in heritability from nature to captivity $\left(\Delta h^{2} \mathrm{~N}\right.$ to $\left.\mathrm{C}\right)$ are determined either by $k$ statistic (WC, WL, LF), or by relationship between all estimates of heritability in nature $v$ s captivity (PC, EF). Changes in $V_{\mathrm{A}}$ determined by $k$ as described in text.

Table 3 Information about additive genetic variance $\left(V_{\mathrm{A}}\right)$ and residual variance $\left(V_{\mathrm{R}}\right)$ that may be derived from known changes in heritability $\left(h^{2}\right)$ and phenotypic variance $\left(V_{\mathrm{P}}\right)$ from nature to captivity

\begin{tabular}{lll}
\hline Pattern $\quad \mathrm{h}^{2}$ & $\mathrm{~V}_{P} \quad \begin{array}{l}\text { Implied } \Delta \text { in } \mathrm{V}_{A} \text { and } \mathrm{V}_{R} \text { from nature } \\
\text { to captivity }\end{array}$ \\
\hline
\end{tabular}

\begin{tabular}{|c|c|c|c|}
\hline 1 & $\mathrm{D}$ & $\mathrm{D}$ & $\begin{array}{l}\text { Decrease } V_{\mathrm{A}} \text {, with no change in } \\
\left.V_{\mathrm{R}} \text { (or smaller than } \Delta V_{\mathrm{A}}\right)\end{array}$ \\
\hline 2 & $\mathrm{D}$ & I & $\begin{array}{l}\text { Increase } V_{\mathrm{R}} \text {, with no change in } \\
V_{\mathrm{A}} \text { (or smaller than } \Delta V_{\mathrm{R}} \text { ) }\end{array}$ \\
\hline 3 & $\mathrm{D}$ & $\mathrm{N}$ & $\begin{array}{l}\text { Not theoretically possible (very } \\
\text { slight decrease in } V_{\mathrm{A}} \text { ) }\end{array}$ \\
\hline 4 & I & $\mathrm{D}$ & $\begin{array}{l}\text { Decrease } V_{\mathrm{R}} \text {, with no change } \\
V_{\mathrm{A}} \text { (or smaller than } \Delta V_{\mathrm{R}} \text { ) }\end{array}$ \\
\hline 5 & I & I & $\begin{array}{l}\text { Increase } V_{\mathrm{A}} \text {, with no change } \\
V_{\mathrm{R}} \text { (or smaller than } \Delta V_{\mathrm{A}} \text { ) }\end{array}$ \\
\hline 6 & I & $\mathrm{N}$ & $\begin{array}{l}\text { Not theoretically possible (very } \\
\text { slight increase in } V_{\mathrm{A}} \text { ) }\end{array}$ \\
\hline 7 & $\mathrm{~N}$ & $\mathrm{D}$ & Decrease $V_{\mathrm{A}}$ and $V_{\mathrm{R}}$ \\
\hline 8 & $\mathrm{~N}$ & I & Increase $V_{\mathrm{A}}$ and $V_{\mathrm{R}}$ \\
\hline 9 & $\mathrm{~N}$ & $\mathrm{~N}$ & No change $V_{\mathrm{A}}$ and $V_{\mathrm{R}}$ \\
\hline
\end{tabular}

$\mathrm{D}, \mathrm{I}$, and $\mathrm{N}$ indicate decrease, increase, and no change, respectively.

unstable, and $h_{\mathrm{N} \beta}^{2}$ was used as a (more conservative) lower bound of heritability instead. There was a trend toward decline in heritability in EF, as it changed from significantly above zero to no different from zero.

A more detailed picture of changes in variance components can be gleaned by combining the above heritability estimates with estimates of total phenotypic variance $\left(V_{\mathrm{P}}\right)$ for the traits in question (Table 3). Patterns in $V_{\mathrm{P}}$ were clearer than those in heritability, due to relatively smaller standard errors: $V_{\mathrm{P}}$ remained constant for WC, increased significantly for PC and WL, and decreased significantly for EF and LF (Table 4). No significant changes were found in heritability for any trait using randomization tests, in the case of PC because the estimate used for lower bound of heritability in nature, $\gamma^{2} h_{N}^{2}$, is associated with wide standard errors. Despite their disparate changes across traits when considered singly, estimates of $V_{\mathrm{P}}$ and $h^{2}$ combine to reveal a striking pattern: $C V_{\mathrm{A}}$ was relatively stable in WC, PC and WL (with very small but sometimes significant increases or decreases, around 1-2\%), but declined significantly in EF and LF, between 5 and $7 \%$. These changes appear to be independent of initial evolvabilities, which though highest in wing colour, are comparable (0-12\%) in all other traits, regardless of trait type.

Hypothesis testing on variance components in this study presents something of a challenge in terms of multiple comparisons. If all traits and statistics considered were independent, Table 4 would contain a total of 5 traits $* 5$ statistics $=25$ independent comparisons. Manly (1997) suggests that in randomization tests, one method of guarding against Type 1 errors is to divide the desired significance level (typically 0.05 ) by the number of independent comparisons made, which would leave $P \leqslant 0.002$ as 'significant' in this case. However, he further points out that any correlations in the data will render this overly conservative. Indeed, the statistics in these 25 comparisons are not independent; within a trait, $V_{\mathrm{A}}$ is positively correlated with $C V_{\mathrm{A}}$ and $h^{2}$, and $V_{\mathrm{A}}$ and $V_{\mathrm{R}}$ are constrained to sum to $V_{\mathrm{P}}$. Furthermore, some traits in this study are correlated phenotypically, though presence or absence of phenotypic correlations may not provide any information about genetic correlations (Roff, 1995). For example, Palmer and Dingle (1986) found a strong and significant negative genetic correlation between fecundity and wing length in $O$. fasciatus, despite finding a 
Table 4 Heritabilities, variance components, and evolvabilities for five traits in O. fasciatus using bootstrap bias-corrected estimates (standard errors in parentheseis)

\begin{tabular}{|c|c|c|c|c|c|c|c|c|}
\hline Trait & Location & $\begin{array}{l}\text { (Table 2) } \\
h_{\min }^{2} \text { or } \mathrm{h}^{2}\end{array}$ & $V_{\mathrm{P}}(S E)$ & $\begin{array}{c}\text { (Table 3) } \\
\text { Pattern }\end{array}$ & $\begin{array}{l}V_{A \min } \text { or } \\
V_{\mathrm{A}}(S E)\end{array}$ & $\begin{array}{l}V_{R \max } \text { or } \\
V_{\mathrm{R}}(S E)\end{array}$ & $\begin{array}{l}C V_{\text {Amin }} \text { or } \\
C V_{\mathrm{A}}(S E)\end{array}$ & $\begin{array}{l}\Delta \min \\
N \text { to } C\end{array}$ \\
\hline Wing colour & $\begin{array}{l}\text { Nature } \\
\text { Captivity } \\
\text { (P) }\end{array}$ & $\begin{array}{c}0.91(0.07) \\
0.92(0.06) \\
0.97\end{array}$ & $\begin{array}{c}113.55(12.66) \\
109.90(11.75) \\
0.64\end{array}$ & 9 & $\begin{array}{c}103.20(14.19) \\
100.93(13.04) \\
0.14\end{array}$ & $\begin{array}{c}8.97(6.50) \\
0.39\end{array}$ & $\begin{array}{c}32.9 \%(2.8) \\
30.6 \%(2.6) \\
0.13\end{array}$ & $-2.3 \%$ \\
\hline Pronotum colour & $\begin{array}{l}\text { Nature } \\
\text { Captivity } \\
(\mathrm{P})\end{array}$ & $\begin{array}{c}0.70(0.45) \\
0.58(0.10) \\
0.26\end{array}$ & $\begin{array}{c}17.81(3.56) \\
\mathbf{3 0 . 1 5}(4.09) \\
0.01\end{array}$ & 2 or 8 & $\begin{array}{c}12.01(9.47) \\
17.47(3.65) \\
0.20\end{array}$ & $\begin{array}{c}5.80(8.06) \\
12.68(3.44) \\
0.04\end{array}$ & $\begin{array}{c}8.9 \%(3.0) \\
10.6 \%(1.1) \\
0.20\end{array}$ & $+1.7 \%$ \\
\hline Wing length & $\begin{array}{l}\text { Nature } \\
\text { Captivity } \\
\text { (P) }\end{array}$ & $\begin{array}{c}0.06(0.13) \\
0.34(0.07) \\
0.23\end{array}$ & $\begin{array}{c}17.49(2.60) \\
27.79(3.05) \\
0.01\end{array}$ & 5 or 8 & $\begin{array}{c}1.03(2.16) \\
9.56(2.03) \\
0.04\end{array}$ & $\begin{array}{c}16.46(3.20) \\
18.22(2.89) \\
0.30\end{array}$ & $\begin{array}{c}\mathbf{0 . 5 \%}(0.4) \\
\mathbf{1 . 2 \%}(0.1) \\
0.004\end{array}$ & $+0.7 \%$ \\
\hline Early fecundity & $\begin{array}{l}\text { Nature } \\
\text { Captivity } \\
\text { (P) }\end{array}$ & $\begin{array}{c}0.44(0.20) \\
0.20(0.18) \\
0.44\end{array}$ & $\begin{array}{c}115.18(19.34) \\
73.8(11.33) \\
0.009\end{array}$ & 7 & $\begin{array}{c}50.17(23.88) \\
14.95(12.34) \\
0.10^{*}\end{array}$ & $\begin{array}{c}65.01(24.37) \\
58.74(16.46) \\
0.38\end{array}$ & $\begin{array}{c}12.3 \%(3.2) \\
4.8 \%(1.8) \\
0.008\end{array}$ & $-7.7 \%$ \\
\hline Later fecundity & $\begin{array}{l}\text { Nature } \\
\text { Captivity } \\
\text { (P) }\end{array}$ & $\begin{array}{c}0.08(0.08) \\
0.07(0.22) \\
0.91\end{array}$ & $\begin{array}{c}149.69(18.01) \\
45.35(9.23) \\
<0.001\end{array}$ & 7 & $\begin{array}{c}11.62(11.79) \\
2.51(9.41) \\
0.05^{*}\end{array}$ & $\begin{array}{c}138.07(19.44) \\
42.84(9.92) \\
<0.001\end{array}$ & $\begin{array}{c}\mathbf{5 . 7 \%}(3.0) \\
\mathbf{1 . 0 \% ( 0 . 2 )} \\
0.007\end{array}$ & $-4.7 \%$ \\
\hline
\end{tabular}

Estimates for first three traits derived from both sexes. $\gamma^{2} h_{\mathrm{N}}^{2}$ used in bootstrap estimate of minimum $h_{\mathrm{N}}^{2}$ for PC, since $k>1$. $h_{\mathrm{N} \beta}^{2}$ used in bootstrap estimate of minimum $h_{\mathrm{N}}^{2}$ for WC, EF, and LF, since $k \leqslant 1$, and in WL, since bias-corrected estimate of $\gamma^{2} h_{\mathrm{N}}^{2}$ less than 0 . Probability levels derived from parametric tests for all $h^{2}$ estimates except PC, or otherwise by randomization (see text for details); significant differences (nature $v s$ captivity) by these tests indicated in bold. Significant differences by $k$ statistic indicated with asterisk. Variance components are in transformed measurement units squared (see Table 2), and multiplied by $10^{2}$ (WC, PC), $10^{3}$ (EF, LF) or 10 (WL) for convenience of presentation.

weaker and positive phenotypic correlation. Unfortunately, the number of families available in this study do not provide sufficient power for examining genetic correlations. Other authors have suggested that heterogeneity in phenotypic variability among traits within populations indicates that they may be treated statistically as independent estimates of shifts across environments (Bryant and Meffert, 1998). Combining these considerations, I take probabilities of 0.01 or less to be 'significant' for randomization tests.

\section{Discussion}

Previous studies have compared heritabilities in nature and in captivity in order to examine the question of the validity of extrapolating more easily obtained laboratory results to natural populations of interest. In the present study, I have used techniques developed in this context to examine an assumption often made in forming captive populations for conservation purposes, that a small number of founders can capture a large proportion of the genetic variation of wild populations. Although my estimates in nature are less than ideal, since they rely on data derived in part from captive individuals, if anything they will be conservative, as they are minima which may be biased downward if additive genetic correlations across environments are not perfect.

In the context of the first question, no significant changes in heritability were observed in any trait in the transition from nature to captivity. However, this cannot be taken as straightforward support for previous claims of a predictable relationship between heritability in nature and captivity (eg, Bitner-Mathé and Klaczko, 1998): the lack of significant differences appears to be due not to small changes in the location of estimates, but to the large errors around those estimates. This is particularly so in the fecundity traits examined, and underscores the shortcomings of studies on single traits in isolation. Had only wing colour been considered, the conclusion that estimates in captivity can readily be extrapolated to nature might seem reasonable, as estimates in both environments are very similar, with small errors. However, when the additional traits are considered, this pattern is much less clear, in keeping with findings summarized across a large number of single-trait studies (Weigensberg and Roff, 1996).

Indeed, large errors in heritability estimates suggest that the other measure of heritable variation used in this study, evolvability, may be a valuable additional metric in comparisons of genetic variance. Although significant heritable variation was detected in a life history and two morphological traits in nature and in three morphological traits in captivity, comparison of these values with other studies emphasizes the variability in heritability in species even within the same environment, across different studies. While in agreement with a previous study finding moderate heritability for early fecundity in captivity $(0.44$ in the present study $v s \quad 0.25-0.31$ in Groeters and Dingle, 1988) and a low minimum heritability for wing length in nature (0.06 compared with 0.10-0.20 in Groeters and Dingle, 1996), the present estimate of heritability of wing length in captivity $(0.34)$ is considerably lower than the range of values uncovered in previous work (0.6-0.87: Palmer and Dingle, 1986; 0.450.53: Dingle et al, 1988; 0.80: Groeters and Dingle, 1996).

The comparisons of evolvability across environments in this study provide additional evidence that the lack of significant change observed in heritability from nature to captivity is likely to stem from large errors, rather than 
from true stability in variance components. Although evolvability remained unchanged in the three morphological traits examined, shifting $1-2 \%$ or less, it declined $5-8 \%$, and significantly, in the fecundity traits. This large and significant decline is striking for a number of reasons. First, changes are inherently more difficult to detect in statistics with the decreased precision imposed by single-sex estimation. Second, estimates of $V_{\mathrm{AN}}$ and $C V_{\mathrm{AN}}$ for these traits are lower bounds of these parameters, such that if anything, true declines in captivity were greater than observed. Finally, the ratio test used to detect declines in evolvability loses power when means between groups differ (Manly, 1997, p. 103), as they did in the case of both EF and LF (Table 1). These same factors also make it less surprising that a change of less than $1 \%$ in evolvability in wing length, which has fewer of these limitations, was significant.

The significant decline in evolvability for EF and LF may be the result of several factors, as they differed from the other traits examined in several respects. Although generation 0 completed its development in nature, these two traits, unlike others, were not measured in fully natural conditions: pairs were mated and eggs were collected in a captive context. However, this would tend to make the estimates from different generations more similar rather than more different. Second, selection may have been another factor depleting additive genetic variation in these traits. Every effort was made to minimize selection for improved captive performance by ensuring that every family was represented in every generation and also randomly selecting individuals within families to be used as parents (Falconer and MacKay, 1996). However, unlike other traits examined, individuals on the low end (or at 0) on the fecundity scale could not, by definition, be represented in the next generation, so any genetic factors associated with poor reproductive performance in captivity were necessarily lost. Finally, although care was taken to sample wild individuals widely and yet within a single subpopulation, it is conceivable that founders came from more than one subpopulation. However, the inflation of genetic variance possible from such mixing would be expected to influence natural and captive estimates equally, and thus is not likely to be a factor contributing to the declines observed in evolvability for fecundity.

Instead, other factors seem more likely to be the cause of the significant declines in evolvability in EF and LF. 'Domesticating' selection reducing additive genetic variance for fecundity could have been generated in the first generation of captivity by gene-by-environment interactions, such that variants were lost who produce well in nature but poorly in captivity. Such interactions can cause changes in additive genetic variance even in the absence of selection, when genetic variants themselves are not lost, but their effects change. Extensive interactions of fecundity with photoperiod (Groeters and Dingle, 1987), temperature (Groeters and Dingle, 1988), and flight activity (Slansky, 1980) have been observed in this species and in closely related ones (Kasule, 1991), consistent with the sharp change in fecundity measures across the two environments seen here. However, whether observed declines may also be due to lower levels of 'stress' in captivity remains unclear (Bijlsma and Loeschcke, 1997).
It is tempting to conclude that the stability of evolvability in WC, PC and WL across the naturecaptivity transition $v s$ its decline in EF and LF represents a fundamental difference between morphological and life-history traits in general. Such a difference could result from the consistent directional selection traits closely correlated with fitness are assumed to experience in nature (Mousseau and Roff, 1987) or from enhanced developmental noise in life-history traits, which may be under the influence of a greater number of loci (Houle, 1992 and references therein), both of which might increase the opportunity for gene-by-environment interactions. However, with so small a sample size (just two 'life-history' traits and three 'morphological' traits, themselves phenotypically correlated), such conclusions would be premature.

Regardless of the reasons behind the difference, an important result is that, though selection or gene-byenvironment interactions may generate significant changes in evolvability in some circumstances, this does not always have to be the case. The conservation implications of stability in evolvability for some traits in the first generation following capture are not trivial: in line with classic theory, it appears possible, at least for some traits, to capture the full compliment of potentially adaptive genetic variation from nature, with even a limited number of founders. If gene-by-environment interactions or selective losses were the rule, fundamental genetic constraints on all traits at the moment of sampling would have to be added to the already considerable list of limitations on the usefulness of captive breeding as a conservation tool (Kleiman et al, 1996).

However, it is sobering to note that the 50 pairs of founders in this study is still greater than the 10 pairs currently considered adequate in conservation contexts (eg, Clark et al, 1997). Given recent advances in applying techniques used in agricultural production to estimate variance components in nondomestic species with complex pedigrees (eg, Milner et al, 2000) it would be of great interest to apply the above methods to endangered species currently in captivity in which wild founders are still alive, to determine whether evolvability can remain stable in nonmodel organisms, even when founder numbers are smaller and drift might be expected to have a more pronounced effect. Such methods also might help identify which among many traits would be useful to monitor in such populations over successive generations. It seems likely that such efforts would be of greater value than simply monitoring heritability, which has been advocated in the past (Cheverud et al, 1994; Lynch, 1996).

\section{Acknowledgements}

Crucial assistance with field collections came from Jon Paul Rodríguez, David Smith and Amy Whorlton, while essential husbandry advice came from Hugh Dingle. I thank Dorothy Feir and Sonia Alteiser for their help obtaining seeds, and many in Princeton's Department of Ecology and Evolutionary Biology (EEB) for help with seed collection and processing. I am grateful to Wolf Blanckenhorn, John Brookfield, Andy Dobson, Peter Grant, Hope Hollocher, Isabel Oliveri, Don Stratton and one anonymous reviewer for their insightful comments 
on this work, as well as to Robert Lacy, Jonathan Ballou, Eric Dyreson, Lukas Keller and Henry Horn for their ideas and advice. This work was conducted with support from the EEB Department of Princeton University, a National Science Foundation Graduate Research Fellowship, the Alfred P Sloane Foundation, and logistical support from the Centro de Ecología of the Instituto Venezolano de Investigaciones Científicas.

\section{References}

Balmford A, Mace GM, Leader-Williams N (1996). Designing the ark: setting priorities for captive breeding. Conserv Biol 10: 719-727.

Bijlsma R, Loeschcke V (1997). Environmental Stress, Adaptation, and Evolution. Birkhauser Verlag: New York.

Bitner-Mathé BC, Klaczko LB (1998). Variation and heritability of aristal morphology in a natural population of Drosophila mediopunctata. Hereditas 128: 67-71.

Blanckenhorn WU (2002). The consistency of quantitative genetic estimates in field and laboratory in the yellow dung fly. Genetica 114: 171-182.

Bryant EH, Meffert LM (1998). Quantitative genetic estimates of morphometric variation in wild-caught and laboratoryreared houseflies. Evolution 52: 626-630.

Bürger R, Lynch M (1995). Evolution and extinction in a changing environment: a quantitative genetic analysis. Evolution 49: 199-213.

Cheverud JM, Routman EJ, Jaquish C, Tardif S, Peterson G, Belfiore $N$ et al (1994). Quantitative and molecular genetic variation in captive cotton-top tamarins (Saguinus oedipus). Conserv Biol 8: 95-105.

Clark KM, Carroll JB, Clark M, Garrett SRT, Pinkus S, Saw R (1997). Capture and survey of Livingstone's fruit bat Pteropus livingstonii in the Comoros Islands: the 1995 expedition. Dodo, J JWPT 33: 20-35.

Coyne JA, Beecham E (1987). Heritability of two morphological characters within and among natural populations of Drosophila melanogaster. Genetics 117: 727-737.

Dingle H (1981). Geographical variation and behavioral flexibility in milkweed bug life histories. In: Denno RF, Dingle H (eds) Insect Life History Patterns: Habitat and Geographical Variation. Springer Verlag: New York, pp 57-73.

Dingle H (1992). Food level reaction norms in size-selected milkweed bugs (Oncopeltus fasciatus). Ecol Entomol 17: 121-126.

Dingle H, Evans KE (1987). Responses in flight to selection on wing length in nonmigratory milkweed bugs, Oncopeltus fasciatus. Entomol Exp Appl 45: 289-296.

Dingle H, Evans KE, Palmer JO (1988). Responses to selection among life-history traits in a nonmigratory population of milkweed bugs (Oncopeltus fasciatus). Evolution 42: 79-92.

Efron B, Tibshirani R (1986). Bootstrap models for standard errors, confidence intervals, and other measures of statistical accuracy. Stat Sci 1: 54-77.

Evans DL (1988). Anti-predatory defenses in the greater milkweed bug. Am Zool 28: 71A.

Falconer DS, MacKay TFC (1996). Introduction to Quantitative Genetics, Fourth Edition. Addison Wesley Longman Limited: Essex, England.

Feir D, Beel C, Willman J (1982). Milkweed pod thresher. Ann Ent Soc Am 75: 353-354.

Groeters FR, Dingle H (1987). Genetic and maternal influences on life history plasticity in response to photoperiod by milkweed bugs. Am Nat 129: 332-346.

Groeters FR, Dingle H (1988). Genetic and maternal influences on life history plasticity in milkweed bugs (Oncopeltus): response to temperature. J Evol Biol 1: 317-333.
Groeters FR, Dingle H (1996). Heritability of wing length in nature for the milkweed bug, Oncopeltus fasciatus. Evolution 50: $442-447$.

Hedrick PW (1986). Genetic polymorphisms in heterogeneous environments: a decade later. Annu Rev Ecol Syst 17: 535-566.

Hoffmann AA, Parsons PA (1991). Evolutionary Genetics and Environmental Stress. Oxford University Press: Oxford.

Houle D (1992). Comparing evolvability and variability of quantitative traits. Genetics 130: 195-204.

Kasule FK (1991). Quantitative variation in adult size and fecundity of the cotton stainer bug Dysdercus fasciatus. Heredity 66: 273-279.

Kleiman DG, Allen ME, Thompson KV, Lumpkin S (eds) (1996). Wild Mammals in Captivity. University of Chicago Press: Chicago.

Koerper KP, Jorgensen CD (1984). Mass-rearing method for the large milkweed bug, Oncopeltus fasciatus (Hemiptera, Lygaeidae). Entomol News 95: 65-69.

Lacy RC (1994). Managing genetic diversity in captive populations of animals. In: Bowles ML, Whelan CJ (eds) Restoration of Endangered Species. Cambridge University Press: Cambridge, pp 63-89.

Leslie JF (1990). Geographical and genetic structure of life history variation in milkweed bugs (Hemiptera: Lygaeidae: Oncopeltus). Evolution 44: 295-304.

Leslie JF, Dingle H (1983). Interspecific hybridization and genetic divergence in milkweed bugs (Oncopeltus: Hemiptera: Lygaeidae). Evolution 37: 583-591.

Letraset Ltd (1998). Pantone Color Paper Selector 1000-Piece Chip Set. Ashford: Kent, UK.

Lynch M (1996). A quantitative-genetic perspective on conservation issues. In: Avise JC (ed) Conservation Genetics: Case Histories from Nature. Chapman Hall: New York, pp 471-501.

Lynch M, Walsh B (1998). Genetics and Analysis of Quantitative Traits. Sinauer Associates: New York.

Manly BFJ (1997). Randomization, Bootstrap, and Monte Carlo Methods in Biology. Chapman \& Hall: London.

Milner JM, Pemberton JM, Brotherstone S, Albon SD (2000). Estimating variance components and heritabilities in the wild: a case study using the 'animal model' approach. J Evol Biol 13: 804-813.

Mousseau TA, Roff DA (1987). Natural selection and the heritability of fitness components. Heredity 59: 181-197.

Norry FM, Vilardi JC, Hasson E (1997). Genetic and phenotypic correlations among size-related traits, and heritability variation between body parts in Drosophila buzzatii. Genetica 101: 131-139.

Palmer JO, Dingle H (1986). Direct and correlated responses to selection among life-history traits in milkweed bugs (Oncopeltus spp.). Evolution 40: 767-777.

Petraitis PS, Beaupre SJ, Dunham AE (2001). ANCOVA: Nonparametric and randomization approaches. In: Scheiner SM, Gurevitch J (eds) Design and Analysis of Ecological Experiments. Oxford University Press: Oxford, pp 116-133.

Prout T, Barker JSF (1989). Ecological aspects of the heritability of body size in Drosophila buzzatii. Genetics 123: 803-813.

Riska B, Prout T, Turelli M (1989). Laboratory estimates of heritabilities and genetic correlations in nature. Genetics 123: 865-871.

Rodríguez-Clark KM (2002). The conservation of quantitative genetic variation in small populations: experiments with Oncopeltus fasciatus (the large milkweed bug). Ph D Thesis, Princeton University.

Roff DA (1995). The estimation of genetic correlations from phenotypic correlations: a test of Cheverud's conjecture. Heredity 74: 481-490.

SAS Institute Inc. (2001). The SAS System 8 e for Windows. SAS Institute Inc.: Cary, NC. 
Scion Corporation (2000). Scion Image for Windows, Beta 4.02, based on NIH Image for Macintosh by Wayne Rasband of National Institutes of Health, USA.

Sgró CM, Hoffmann AA (1998). Heritable variation for fecundity in field-collected Drosophila melanogaster and their offspring reared under different environmental temperatures. Evolution 52: 134-143.

Simons AM, Roff DA (1994). The effect of environmental variability on the heritabilities of traits of a field cricket. Evolution 48: 1637-1649.
Slansky FJ (1980). Food consumption and reproduction as affected by tethered flight in female milkweed bugs (Oncopeltus fasciatus). Entomol Exp Appl 28: 277-286.

Weigensberg I, Roff DA (1996). Natural heritabilities: can they be reliably estimated in the laboratory? Evolution 50: 2149-2157.

Willis JH, Orr HA (1993). Increased heritable variation following population bottlenecks: the role of dominance. Evolution 47: 949-957. 